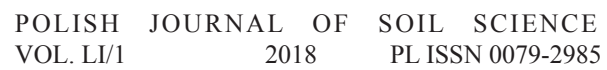

DOI: $10.17951 / \mathrm{pjss} / 2018.51 .1 .103$

\author{
ALEKSANDRA KRÓL*, TOMASZ ŻYŁOWSKI*, JERZY KOZYRA*, \\ JERZY KSIĘŻAK**
}

\title{
SOIL MOISTURE UNDER NO-TILLAGE AND TILLAGE SYSTEMS IN MAIZE LONG-TERM EXPERIMENT
}

Received: 5.03 .2018

Accepted: 28.03 .2018

Abstract. The aim of the study was to evaluate the impact of conventional till (CT) and no-till (NT) cultivation systems in a long-term experiment with maize on soil water dynamics using continuous soil moisture (SM) measurements in the 2014, 2015, 2016 vegetation seasons. The ability of HERMES model to simulate SM was also evaluated in Polish conditions. The long-term experiment with maize is located in the Grabów Experimental Farm of Institute of Soil Science and Plant Cultivation - State Research Institute in the Masovian Voivodeship - Central Poland $\left(51^{\circ} 21^{\prime} 18^{\prime \prime} \mathrm{N}, 21^{\circ} 40^{\prime} 09^{\prime \prime} \mathrm{E}\right)$. The HERMES model was calibrated by modification of temperature sums in crop parameters file and capacity parameters (field capacity and wilting point) of the experimental site. The results show that NT system has a positive impact on soil water content. However, this improvement is dependent on a year, phenological phase and soil layer. The results showed also that calibrated (until now) model HERMES is able to simulate SM in a wet year. For simulation of SM in a dry year there is still need for future improvement of calibration parameters.

Keywords: maize cultivation, soil moisture, HERMES, conventional till and no-till system

* Department of Bioeconomy and Systems Analysis, Institute of Soil Science and Plant Cultivation - State Research Institute, 8 Czartoryskich St, 24-100 Puławy, Poland; corresponding author: akrol@iung.pulawy.pl

** Department of Forage Crop Production, Institute of Soil Science and Plant Cultivation State Research Institute, 8 Czartoryskich St, 24-100 Puławy, Poland. 


\section{INTRODUCTION}

The practices of making agriculture less susceptible to negative impact of climate change focus mainly on soil management, which may improve soil water content (SWC) and reduce crop water stress during drought conditions (Basche et al. 2016). For this purpose, a concept of conservation agriculture that combines different methods towards minimizing the intensity of tillage is proposed (Busari et al. 2015), with the use of different traditional methods to conserve the soil moisture (e.g. mulching, rotation, legumes), reduce production costs and soil erosion (Holland 2004). For better understanding of the role of different agricultural practices in adaptation to climate change, the analysis of management of soil water and carbon budgets are necessary (Chi et al. 2016). In the literature there is a number of studies analysing the impact of tillage practices on soil water balance in conventional tillage (Chi et al. 2016, Liu et al. 2013, Mkoga et al. 2010, Mupangwa and Jewitt 2011, Sommer et al. 2012), reduced tillage (RT) (Liu et al. 2013), no-tillage (NT) (Chi et al. 2016, Liu et al. 2013, Mupangwa and Jewitt 2011, Sommer et al. 2012) and minimum tillage systems (MT) (Fabrizzi et al. 2005). These studies, among others, evaluated the impact of tillage practices on evapotranspiration rate (Chi et al. 2016, Sommer et al. 2012) or soil water (Fabrizzi et al. 2005, Liu et al. 2013, Mkoga et al. 2010). In the mentioned references, the soil moisture (SM) was measured (Fabrizzi et al. 2005, Liu et al. 2013) and simulated by crop growth models (Mkoga et al. 2010, Mupangwa and Jewitt 2011, Liu et al. 2013, Sommer et al. 2012).

Different tillage practices directly or indirectly influence the ability of the soil to adsorb and retain water from precipitation or irrigation (Blanco-Canqui et al. 2017). Depending on the degree of interference from tillage systems, changes can be observed in soil water content, aeration and soil temperature, which influence the decomposition rate of residues left in the soil (Copec et al. 2016). It has been shown that reduction of tillage practices leads to the change of soil properties, for instance, of bulk density and the soil organic matter (SOM) content. The SOM has a key impact on the structure and properties of the soil and the possibility of water retention. Conservation agricultural systems increase plant available water in the upper $(0-10 \mathrm{~cm})$ soil layer as compared to till systems. It has been well established that increasing amounts of crop residues on the soil surface can reduce the evaporation rate (Naresh et al. 2013).

Czyż and Dexter (2008) found that RT increased SWC throughout the soil profile of $0-70 \mathrm{~cm}$ on winter wheat cultivation, but the effect of tillage was mostly found only at the top depth $(0-33 \mathrm{~cm})$ and depended on the year. The evaluation was based on sampling soil cores and not on continuous measurements. According to Czyż (2011), direct drilling practices (NT system) increased the SWC of the top layer of soil $(0-10 \mathrm{~cm})$, compared to CT in maize. Włodek and Biskupski (2011) reported that tillage system does not permanently or uniformly 
affect water retention on loamy sand soil in the rotation: maize - spring wheat winter wheat. Direct sowing into NT soil contributed to the formation of a layer of mulch on the soil surface which had a positive effect on SWC, especially on dates preceded by periods with little amount of precipitation and high temperature. With a high level of waterlogging, differences in water content in the compared cultivation methods are negligible. Changes in the amount of water in the soil are characterized by high dynamics. Their directions depend on many factors such as: physical properties of the soil, surface conditions of the field or weather course (Włodek et al. 2008).

The aim of the study was to evaluate the impact of different maize cultivation practices in a long-term experiment with maize on soil water using continuous soil moisture measurement. Previous studies related to these issues on the considered long-term experiment were not based on continuous soil measurements. It should also be pointed out that the analysis was carried out after the subsequent years of maintaining previous evaluation. Additionally, the ability of HERMES model to simulate soil moisture was also presented.

\section{MATERIALS AND METHODS}

The continuous SM measurements were conducted in a long-term experiment in the experimental farm of the Institute of Soil Science and Plant Cultivation - State Research Institute, Grabów, Masovian Voivodeship, Central Poland $\left(51^{\circ} 21^{\prime} \mathrm{N} 21^{\circ} 40^{\prime} \mathrm{E}, 166 \mathrm{~m}\right.$ a.s.l.) on a loamy sand soil (Czyż 2011). The long-term experiment was established in 2004. The study area has a continental climate with an average annual rainfall of $630 \mathrm{~mm}$. At the experimental site, the soil moisture measurements were taken at two objects where maize was grown under:

1. No-tillage (NT), direct drilling with surface mulching (chopped maize silage);

2. Conventional tillage (CT), plough tillage (to $23 \mathrm{~cm}$ depth) with surface mulching (chopped maize silage).

The soil at the experimental field was determined as loamy sand for 0-20 $\mathrm{cm}$ soil layer and below $35 \mathrm{~cm}$. The SOM was greater under NT than CT system by $0.16 \%$ and $0.06 \%$ up to $20 \mathrm{~cm}$ and more than $35 \mathrm{~cm}$ of soil depth, respectively. In the years 2007-2009, mean values of soil bulk density to the depth of $35 \mathrm{~cm}$ were significantly higher in NT than in CT system by $0.12 \mathrm{Mgm}^{-3}(8 \%)$ (Czyż 2011).

For determination of SM in NT and CT systems of maize cultivation, eight (four per one object) SM sensors EC5 (Decagon Device, USA), with accuracy of about $\pm 3 \%$ volumetric water content (VWC) were placed at the $15 \mathrm{~cm}$ and $45 \mathrm{~cm}$ depth. The measurements were taken continuously with 10-minute inter- 
vals using data loggers in 2014, 2015 and 2016. SM sensors were installed after each planting season, when the conditions allowed for field work and location of plants was visible. SWC up to $60 \mathrm{~cm}$ depth was determined as the sum of the water content in these both layers. Soil available water was calculated as maximum water holding capacity (24\%) minus permanent wilting point (13\%) (Hernández et al. 2015). Soil water content was expressed in $\mathrm{mm}$ on the base of measured VWC for the $0-30 \mathrm{~cm}$ and $30-60 \mathrm{~cm}$ soil layers. Additionally, the SWC was analysed in three different phenological stages of maize: S1 - from emergence to flowering, S2 - from flowering to milk maturity, S3 - from milk maturity to physiological maturity.

During the vegetative season, the beginnings of the phenological stages were observed including sowing and harvesting dates. At the experimental site the automatic weather station is placed, conducting measurement of rainfall, temperature, wind speed, humidity, and sunshine duration replaced in 2014 with global radiation.

The statistical analysis was done with the RStudio (Version 1.0.136 - 20092016 RStudio, Inc) using the package "agricolae". Mean SWC separations were based on least significant differences (LSD test), which were considered significant at $\mathrm{p} \leq 0.05$.

Crop growth HERMES model (Kersebaum 1995) is able to simulate soil water dynamics based on the weather data and the basic information about soil management. The HERMES model is a one-dimensional, multi-crop and multiyear model. It can be used for daily time step simulation of water and nitrogen dynamics in agro-ecosystems (Kersebaum et al. 2009). The model takes into account nitrogen mineralization, denitrification, crop growth, transport of water and nitrogen (Kersebaum 2007). The HERMES model may be used to evaluate different crop management practices, such as nitrogen fertilization (Kersebaum et al. 2009). The required daily weather data include temperature, precipitation, vapor pressure deficit at 2 p.m. and global radiation which can be replaced with sunshine duration. The soil information is required for every $10 \mathrm{~cm}$ of soil layer. The soil properties may be determined by the user based on field measurement or they may be assigned to soil texture class. For plough layer, the obligatory soil information consists of: SOM and $\mathrm{C} / \mathrm{N}$ ratio. Also, additional information about the stone content, SM and ground water level is necessary (Kersebaum et al. 2005). Essential data for management are: crop species, term of sowing and harvesting, as well as information about soil tillage (date, depth), irrigation (date, amount) and fertilization (date, amount, type of fertilizer) (Kersebaum 2007).

The HERMES model was calibrated in three steps and the data from the experimental field (from 2004 to 2015 for maize phenology and from 2014 to 2015 for soil capacity parameters) were used for this purpose. Firstly, capacity parameters (field capacity and wilting point) were calibrated with the observed 
minimum and maximum soil moisture. Secondly, because the length of development stages depends on the accumulated average daily air temperatures, the required temperature sum was adjusted to observed values for each development stage. The temperature sum was primarily adjusted against onsets of maize phenological phases and, finally, against soil moisture. Thirdly, due to the fact that crop coefficients ( $k c$ factors) are linked to the development stage, the calibration can be continued by changing the $k c$ factor for each development stage to adjust simulated soil moisture to the observed values (Kersebaum 2011). Kc factors show the relationship between the reference and crop evapotranspiration (Doorenbos 1975). Root Mean Square Error (RMSE) was used for a statistical evaluation of the relationship between the measured and modelled maize phenology in 2014 and 2015.

\section{RESULTS}

\section{Weather conditions}

The mean daily global radiation, mean air temperature and cumulative rainfall during the growing seasons from 2014 to 2016 are presented in Table 1. In the vegetative season from April to October in 2014, the rainfall sum was 579 $\mathrm{mm}$, in $2015-342 \mathrm{~mm}$ and in $2016-388 \mathrm{~mm}$. It is important to remark that in 2015, in April, June, August, and October the monthly precipitation sum was lower than $50 \mathrm{~mm}$, and in August it was only $6 \mathrm{~mm}$. The mean air temperature during the growing season was $14.4^{\circ} \mathrm{C}$ in $2014,14.5^{\circ} \mathrm{C}$ in 2015 , and $14.7^{\circ} \mathrm{C}$ in 2016. The weather data shows that analysed years were very similar in case of thermal condition, whilst 2014 was significantly different from 2015 and 2016 in terms of precipitation.

Table 1 . Mean daily global radiation, mean air temperature, cumulative rainfall during

the growing seasons in the years 2014-2016 in the Grabów Experimental Station

\begin{tabular}{cccccccccc}
\hline \multirow{2}{*}{ Month } & \multicolumn{3}{c}{$\begin{array}{c}\text { Global radiation } \\
\left(\mathrm{Jcm}^{-2} \mathrm{~d}^{-1}\right)\end{array}$} & \multicolumn{3}{c}{ Mean air temperature $\left({ }^{\circ} \mathrm{C}\right)$} & \multicolumn{3}{c}{$\begin{array}{c}\text { Rainfall } \\
(\mathrm{mm})\end{array}$} \\
\cline { 2 - 12 } & 2014 & 2015 & 2016 & 2014 & 2015 & 2016 & 2014 & 2015 & 2016 \\
\hline IV & 1338 & 1538 & 1355 & 10.0 & 8.1 & 9.2 & 55 & 35 & 45 \\
\hline V & 1733 & 1709 & 2125 & 13.5 & 12.7 & 14.9 & 171 & 106 & 39 \\
\hline VI & 1853 & 2177 & 2340 & 15.6 & 16.9 & 18.7 & 99 & 30 & 60 \\
\hline VII & 1961 & 2191 & 1852 & 20.4 & 19.7 & 19.2 & 113 & 52 & 82 \\
\hline VIII & 1549 & 1997 & 1768 & 17.9 & 22.1 & 18.1 & 97 & 6 & 54 \\
\hline IX & 1200 & 1042 & 1325 & 14.4 & 15.0 & 15.7 & 16 & 93 & 20 \\
\hline X & 706 & 702 & 483 & 9.2 & 7.0 & 7.4 & 28 & 20 & 88 \\
\hline IV-X & $\mathbf{1 4 7 7}$ & $\mathbf{1 6 2 2}$ & $\mathbf{1 6 0 7}$ & $\mathbf{1 4 . 4}$ & $\mathbf{1 4 . 5}$ & $\mathbf{1 4 . 7}$ & $\mathbf{5 7 9}$ & $\mathbf{3 4 2}$ & $\mathbf{3 8 8}$ \\
\hline
\end{tabular}




\section{Soil water content}

The SWC (from 0 to $60 \mathrm{~cm}$ depth) in NT and CT systems (Figure 1) was, in general, higher than $60 \%$ of available water (AW) during 2014 and 2016. In 2015, during phases: S2 and S3, SWC in CT system was lower than $60 \%$ of AW, but not in the NT system. The SWC up to $60 \mathrm{~cm}$ depth (Table 3) was significantly higher in NT than in CT system throughout the analysed seasons, but the difference varied between years, phenological stages and evaluated layers (Table 2 and Table 3). Up to $60 \mathrm{~cm}$ the SWC was greater under NT than CT system from $6 \%$ in 2014 during the phase S1 to $82 \%$ in 2016 during the phase S3. The SWC up to $30 \mathrm{~cm}$ was significantly higher under NT system in reference to CT system from $14 \%$ in 2014 to $59 \%$ in 2015. In 2014, in the 30 to $60 \mathrm{~cm}$ soil layer, SWC in NT system was not statistically different from SWC in till system, whilst in 2015 and 2016, SWC under NT was significantly higher than under CT by 49 and $47 \%$, respectively.

Table 2. Soil water content $(\mathrm{mm})$ in layers $(0-30 \mathrm{~cm}$ and $0-60 \mathrm{~cm})$ under different tillage systems and annual variety

\begin{tabular}{cccc}
\hline \multirow{2}{*}{ Tillage system } & \multicolumn{4}{c}{ Year } \\
\cline { 2 - 4 } & \multicolumn{4}{c}{2014} & 2015 & 2016 \\
\hline \multicolumn{5}{c}{$0-30 \mathrm{~cm}$} \\
\hline CT & $60.4 \mathrm{a}$ & $34.4 \mathrm{~b}$ & $32.6 \mathrm{~b}$ \\
\hline NT & $68.9 \mathrm{c}$ & $43.9 \mathrm{~d}$ & $51.9 \mathrm{e}$ \\
\hline \multicolumn{4}{c}{$30-60 \mathrm{~cm}$} \\
\hline CT & $59.7 \mathrm{a}$ & $30.4 \mathrm{~b}$ & $31.8 \mathrm{~b}$ \\
\hline NT & $60.2 \mathrm{a}$ & $45.3 \mathrm{c}$ & $46.7 \mathrm{c}$ \\
\hline
\end{tabular}

Mean values in the same layer followed by different letters are significantly different $(p<0.05)$

Table 3. Soil water content $(\mathrm{mm})$ under different tillage systems and phenological phases $(0-60 \mathrm{~cm})$

\begin{tabular}{cccccccccc}
\hline \multirow{2}{*}{$\begin{array}{l}\text { Tillage } \\
\text { system }\end{array}$} & \multicolumn{9}{c}{ Year } \\
\cline { 2 - 11 } & S1 & S2 & S3 & S1 & S2 & S3 & S1 & S2 & S3 \\
\hline CT & $122.4 \mathrm{a}$ & $118.7 \mathrm{~b}$ & $117.9 \mathrm{~b}$ & $92.0 \mathrm{a}$ & $36.1 \mathrm{~d}$ & $35.7 \mathrm{~d}$ & $79.9 \mathrm{a}$ & $57.7 \mathrm{~b}$ & $48.1 \mathrm{c}$ \\
\hline NT & $129.7 \mathrm{c}$ & $128.3 \mathrm{c}$ & $136.6 \mathrm{~d}$ & $115.9 \mathrm{~b}$ & $64.3 \mathrm{c}$ & $56.8 \mathrm{c}$ & $108.8 \mathrm{~d}$ & $96.8 \mathrm{e}$ & $87.7 \mathrm{f}$ \\
\hline \multicolumn{7}{l}{ Mean values in the same year followed by different letters are significantly different $(\mathrm{p}<0.05)$} \\
\hline
\end{tabular}



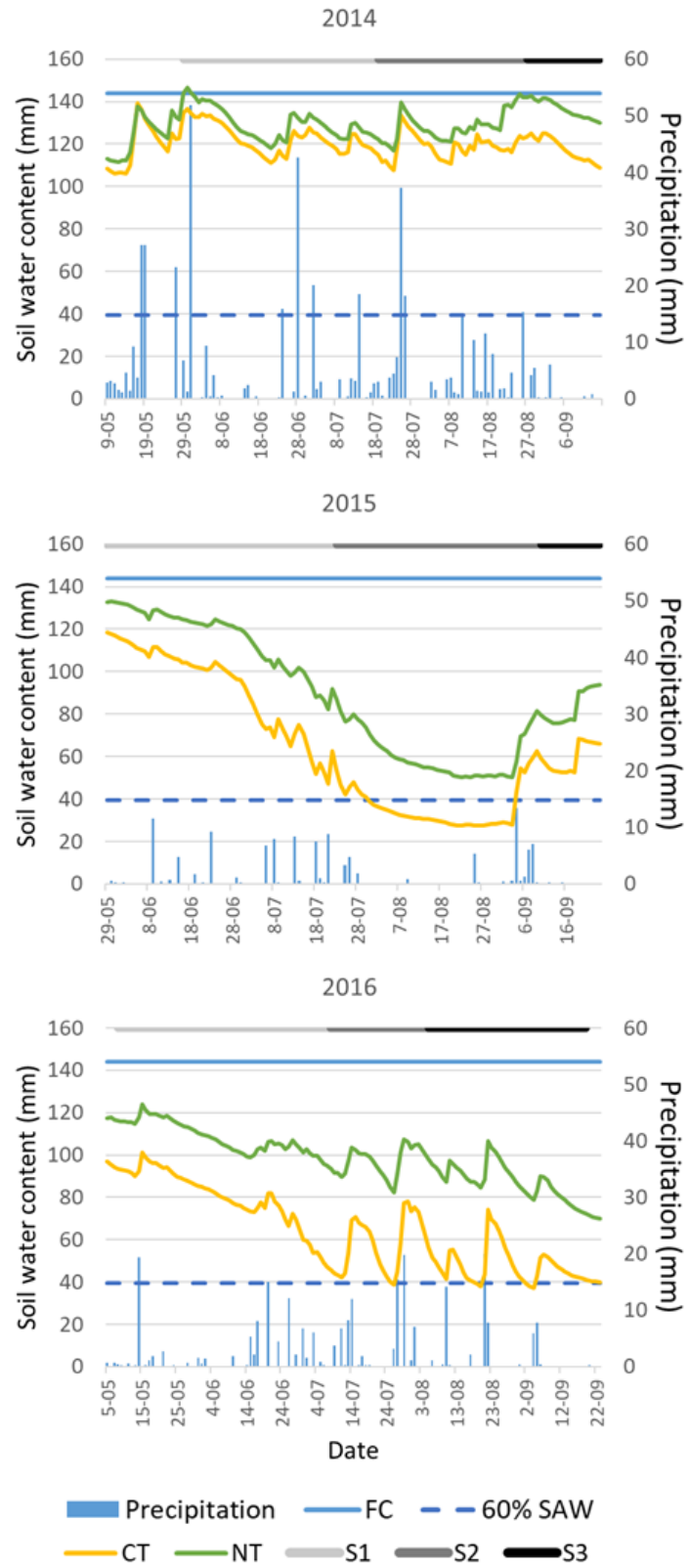

Fig. 1. Soil water content $(\mathrm{mm})$ to the depth of $60 \mathrm{~cm}$ as a function of dates, for maize cultivation under two tillage systems (CT and NT) in 2014, 2015 and 2016. The yellow and green lines correspond to soil water content in CT and NT system, respectively. Upper blue lines and bottom dashed lines indicate FC (maximum soil water holding capacity) and $60 \%$ of SAW, respectively. Horizontal grey lines indicate phenological stages: S1 - from emergence to flowering (the beginning of the season), S2 - from flowering to milk maturity (the middle of the season), and S3 from milk maturity to physiological maturity (the end of the season) 
The aim of this task was to assess the possibility of HERMES model use for simulating soil moisture in CT and NT systems. Calibration of the temperature sum parameter significantly improved the adaptation of HERMES model for simulating maize phenology. Without calibration, maize development did not achieve phase 7 (grain filling II), and in 2014, it did not even achieve phase 6 (grain filling I). After calibration, RMSE ranged from 2.0 (from sowing to emergence) to 7.1 days (from sowing to grain filling II) (Table 4).

Table 4. Root mean square error for maize development stages (number of days from sowing)

\begin{tabular}{ccccccc}
\hline \multirow{2}{*}{ Simulation } & \multicolumn{5}{c}{ Development stage } \\
\cline { 2 - 7 } & Emergence & $\begin{array}{c}\text { Stem } \\
\text { elongation }\end{array}$ & $\begin{array}{c}\text { Tassel } \\
\text { elongation }\end{array}$ & Flowering & $\begin{array}{c}\text { Grain } \\
\text { filling I }\end{array}$ & $\begin{array}{c}\text { Grain } \\
\text { filling II }\end{array}$ \\
\hline Without cal. & 2.3 & 12.5 & 9.1 & 6.5 & 40.2 & - \\
\hline With cal. & 2.0 & 6.8 & 6.6 & 6.6 & 6.6 & 7.1 \\
\hline
\end{tabular}

The mean RMSE value of soil moisture simulation (Table 6) at $15 \mathrm{~cm}$ depth for 2014 was $1.7 \%$ VWC (7\%) and $2.4 \%$ VWC (12\%), respectively in NT and CT systems. At the $45 \mathrm{~cm}$ depth, the simulation of SM for 2014 achieved the RMSE value of $2.9 \%$ VWC (14\%) and 1.6\% VWC (8\%), for NT and CT systems, respectively. For 2014, HERMES (Figure 2) has overestimated the SM under NT system at $15 \mathrm{~cm}$ depth and under CT system at $45 \mathrm{~cm}$ depth, and underestimated it under NT system at $45 \mathrm{~cm}$ depth and CT system at $15 \mathrm{~cm}$ depth. For 2015, it has overestimated the SM under NT and CT systems at $15 \mathrm{~cm}$ depth, while underestimated it under both systems at $45 \mathrm{~cm}$ depth (Table 5). All the obtained results of SM

Table 5. The mean observed and simulated soil moisture in NT and CT systems (\% VWC)

\begin{tabular}{|c|c|c|c|c|c|c|c|c|}
\hline \multirow{4}{*}{$\begin{array}{l}\text { Development } \\
\text { stage }\end{array}$} & \multicolumn{8}{|c|}{ Years } \\
\hline & \multicolumn{4}{|c|}{2014} & \multicolumn{4}{|c|}{2015} \\
\hline & \multicolumn{2}{|c|}{ Observation } & \multicolumn{2}{|c|}{ Simulation } & \multicolumn{2}{|c|}{ Observation } & \multicolumn{2}{|c|}{ Simulation } \\
\hline & NT & $\mathrm{CT}$ & NT & $\mathrm{CT}$ & NT & CT & NT & $\mathrm{CT}$ \\
\hline \multicolumn{9}{|c|}{$15 \mathrm{~cm}$ depth } \\
\hline S1 & 22.8 & 20.3 & 22.7 & 21.8 & 19.0 & 15.3 & 11.1 & 10.2 \\
\hline S2 & 23.0 & 19.9 & 23.3 & 22.3 & 9.6 & 6.1 & 3.6 & 2.7 \\
\hline S3 & 23.5 & 19.6 & 22.3 & 21.2 & 8.9 & 7.0 & 3.5 & 2.6 \\
\hline Mean of S1-S3 & 23.1 & 20.0 & 22.8 & 21.7 & 12.5 & 9.5 & 6.1 & 5.2 \\
\hline \multicolumn{9}{|c|}{$45 \mathrm{~cm}$ depth } \\
\hline S1 & 20.1 & 20.3 & 23.3 & 21.3 & 19.7 & 15.4 & 20.2 & 18.3 \\
\hline $\mathrm{S} 2$ & 20.1 & 19.8 & 20.7 & 18.8 & 11.8 & 5.9 & 12.3 & 9.4 \\
\hline S3 & 21.9 & 19.4 & 20.0 & 17.8 & 10.1 & 4.9 & 10.5 & 6.4 \\
\hline Mean of S1-S3 & 20.7 & 19.9 & 21.3 & 19.3 & 13.9 & 8.7 & 14.3 & 11.3 \\
\hline
\end{tabular}



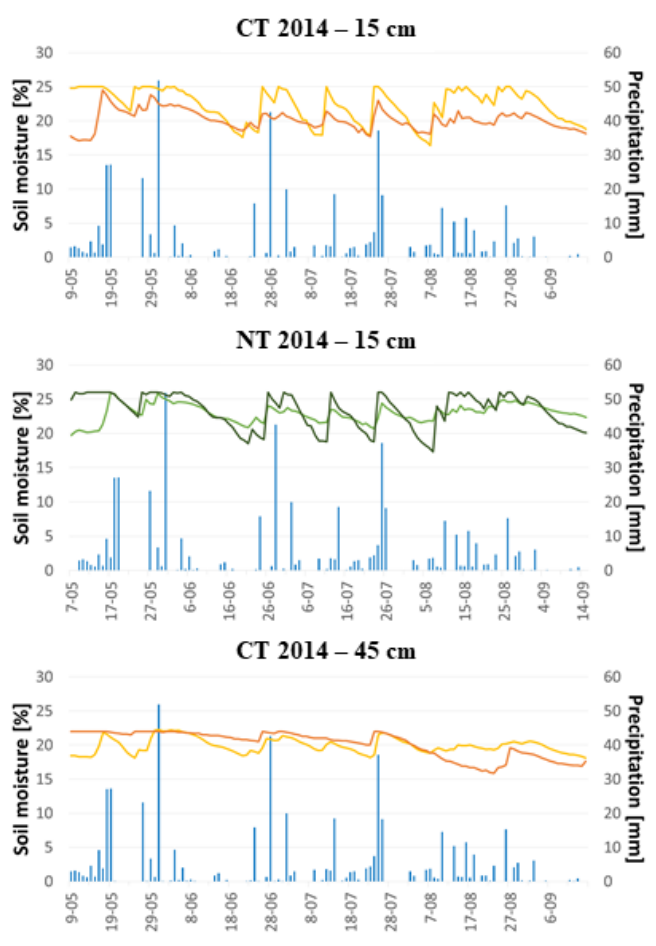

NT $2014-45 \mathrm{~cm}$

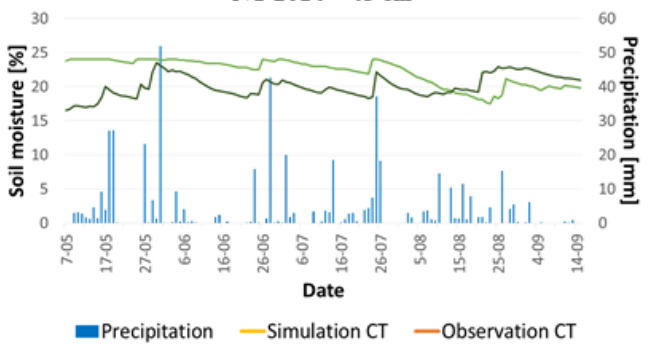

-Simulation NT -Observation NT

Fig. 2. Comparison of simulated and observed SM for maize cultivation under CT and NT systems at $15 \mathrm{~cm}$ and $45 \mathrm{~cm}$ depth in 2014

simulation at 15 and $45 \mathrm{~cm}$ depth for the year 2014 are good (RMSE less than $20 \%$ ), even some of them are excellent (less than 10\%), e.g. $6 \%$ for S3 period in NT system. The SM simulation results for 2015 are mostly poor (greater than $30 \%$ ), whereas at $45 \mathrm{~cm}$ depth for CT system simulation, the results are fair for S1 and S3 periods (RMSE is greater than $20 \%$ and less than $30 \%$ ), and for NT system the results are even excellent (less than 10\%) (Ahmadi et al. 2015). The achieved poor results for 2015 indicate the need for improvement of calibration to obtain satisfactory results. The field experiment is still being conducted and additional measurements are carried out (e.g. LAI). 
At the depth of $15 \mathrm{~cm}, \mathrm{SM}$ (Table 5) under NT was higher than under CT system in 2014 by $3.1 \%$ VWC (15\%) according to measuring values, and $1.1 \%$ VWC (5\%) according to simulation with the HERMES model and in 2015, by $3.0 \%$ VWC (32\%) and $0.9 \%$ VWC (17\%), respectively. Whereas at the depth of $45 \mathrm{~cm}$, the observed and simulated soil moisture was greater in NT system with reference to CT system in 2014 by $0.8 \% \mathrm{VWC}(4 \%)$ and $2.0 \% \mathrm{VWC}(10 \%)$ and in 2015 , by $5.2 \%$ VWC (60\%) and 3.0\% VWC (27\%), respectively.

Table 6. Evaluation of the simulation of soil moisture by the calibrated HERMES model according to root mean square error $(\mathrm{mm})$

\begin{tabular}{ccccc}
\hline \multirow{2}{*}{$\begin{array}{c}\text { Development } \\
\text { stage }\end{array}$} & \multicolumn{5}{c}{ Years } \\
\cline { 2 - 5 } & NT & CT & NT & CT \\
\hline \multicolumn{5}{c}{$15 \mathrm{~cm}$ depth } \\
\hline S1 & $1.5(7 \%)$ & $2.1(10 \%)$ & $9.0(48 \%)$ & $6.5(43 \%)$ \\
\hline S2 & $2.0(8 \%)$ & $3.0(15 \%)$ & $6.4(66 \%)$ & $3.7(60 \%)$ \\
\hline S3 & $1.4(6 \%)$ & $2.0(10 \%)$ & $6.2(70 \%)$ & $5.7(82 \%)$ \\
\hline Mean of S1-S3 & $\mathbf{1 . 7 ( 7 \% )}$ & $\mathbf{2 . 4 ( 1 2 \% )}$ & $\mathbf{7 . 9}(\mathbf{6 3 \%})$ & $\mathbf{5 . 7}(\mathbf{6 1 \%} \%)$ \\
\hline S1 & $3.3(16 \%)$ & $1.2(6 \%)$ & $0.9(4 \%)$ & $3.3(22 \%)$ \\
\hline S2 & $2.7(14 \%)$ & $2.1(10 \%)$ & $0.6(5 \%)$ & $3.7(63 \%)$ \\
\hline S3 & $1.8(8 \%)$ & $1.5(8 \%)$ & $0.5(5 \%)$ & $1.5(30 \%)$ \\
\hline Mean of S1-S3 & $\mathbf{2 . 9 ( 1 4 \% )}$ & $\mathbf{1 . 6 ( 8 \% )}$ & $\mathbf{0 . 7}(\mathbf{5 \%})$ & $\mathbf{3 . 2 ( 3 6 \% )}$ \\
\hline
\end{tabular}

\section{DISCUSSION}

Greater SM under NT in relation to CT system has been also presented in the previous studies. The results obtained by Czyż and Dexter (2010) from the same experimental field showed that in the years 2007-2009, SM at 0 to $10 \mathrm{~cm}$ depth, and in 2009 at 0 to $20 \mathrm{~cm}$ depth is higher in NT than in CT system. The results obtained by Blecharczyk et al. (2004) and Sommer et al. (2012) also showed greater SM in NT than in CT system in 0-20 cm and 0-15 cm soil layer, respectively. The study conducted by Liu et al. (2013) indicated that SWC (0-30 cm) was greater under NT than CT practices by 10-24\%. Su et al. (2007) additionally showed that NT improved fallow rainfall storage efficiency in comparison to $\mathrm{CT}$, especially during dry growing seasons as we proved in the study. Blecharczyk et al. (2004, 2007) and Małecka-Jankowiak et al. (2015) observed that the effect of NT system depends on the soil depth. At the depth of $0-5 \mathrm{~cm}, \mathrm{SWC}$ and bulk density was greater and capillary water capacity was lower in NT than in CT system. At the depth of 10-20 cm, only bulk density was greater in NT than in CT system, whereas SWC and capillary water capacity were lower. Małecka-Jankowiak et al. (2015) also obtained results 
indicating that at the deeper level $(10-20 \mathrm{~cm})$ for narrow-leaved lupine, water content may be greater in NT than in CT system as it is shown in this study. Czyż and Dexter (2010) and Machul (2007) reported greater SOM in NT than in CT system, which may result in better water retention. The results obtained by Bednarek et al. (2015) did not show significant differences between various tillage combinations in the diversity of humus fraction after one year from implementation of the different cultivation systems. The authors noted the need for the research continuation due to the fact that the differences may appear in few years. The results obtained by Machul (2007) showed that NT system mainly leads to a reduction of total porosity, whereas in the results achieved by Włodek et al. (2007) from very loamy sand $(0-25 \mathrm{~cm})$ in the years $2003-$ 2005 there is no clear effect of tillage systems on soil retention changes, but the smallest water loss was obtained in RT system in maize cultivation and in direct sowing in spring barley cultivation.

Calibration results were satisfactory and similar or lower than those obtained in the literature for this as well as for other models. Pohanková et al. (2013) evaluated the accuracy of HERMES model simulation of flowering and maturity onset for winter wheat in Czech Republic conditions and reported RMSEs of 5.1 and 4.3 days, respectively, which agreed with the results of the study (6.6 days). Pohanková et al. (2013) also showed that DAISY model was more accurate for simulation of flowering and maturity onset with reported RMSEs of 4.5 and 3.5 days. Palosuo et al. (2011) and Rötter et al. (2012) compared several crop simulation models and showed that the most accurate estimates for winter wheat maturity were obtained by DSSAT and DAISY models and for spring barley - by STICS and WOFOST. Maturity onset for winter wheat and spring barley obtained by the HERMES model were reported with RMSE greater than 12 and less than 8 days, respectively. The results of reported RMSE of winter wheat maturity simulation obtained by Trnka et al. (2004) with CERES-wheat were similar (8 days).

The study conducted by Graß et al. (2015) also showed underestimation of SM at 30-60 cm depth and presented overestimation at 60-90 cm depth. In 2014 , the simulations of SM at the upper soil depth $(15 \mathrm{~cm})$ were better estimated than in the deeper layer $(45 \mathrm{~cm})$ as was also showed in the results presented by Michalczyk et al. (2014). In 2015, the situation was reversed. The shape of simulated curves of SM for both tillage practices and depths mostly well corresponded to the shape of the observed soil moisture curves, as was presented in the study of Wimmerova et al. (2016). The study conducted by Kersebaum (2007) compared several crop growth models with the soil water content at 0-90 cm. The best performance of soil water content was by CERES model, for which the RMSE was the lowest (14 mm), while for the HERMES model, the RMSE was higher than $20 \mathrm{~mm}$, and for AGROSIM, higher than $40 \mathrm{~mm}$. The HERMES model, similarly to the AquaCrop model, showed insufficient accu- 
racy in simulating soil water content in severe water stress, which was suggested because of insufficient parametrisation of water uptake from the soil, that depends on root distribution and biomass development (Ahmadi et al. 2015).

\section{CONCLUSIONS}

1. NT system increased SWC compared to CT throughout the analysed soil layers: 0-30 cm (34\%), 30-60 cm (32\%) and 0-60 $\mathrm{cm} \mathrm{(42 \% )} \mathrm{on}$ a loamy sand soil at RZD Grabów. However, the difference between the two tillage systems in SWC was dependent on year, phenological phase and soil layer.

2. NT system improved SM in maize cultivation at 15 and $45 \mathrm{~cm}$ depth in comparison with CT system. The measurements show that at the depth of $15 \mathrm{~cm}$, NT increased SM by 15\% and 32\% in 2014 and 2015, respectively, while at the depth of $45 \mathrm{~cm}$, the improvement values were $4 \%$ in 2014 and $60 \%$ in 2015.

3. The SM at 15 and $45 \mathrm{~cm}$ depth was simulated satisfactorily in 2014 . It was concluded that the HERMES model provided good estimation (RMSE less than $20 \%$ ) of SM at 15 and $45 \mathrm{~cm}$ depths in wet year (2014) under NT and CT systems of maize cultivation on loamy sand in Central Poland. However, the obtained poor results (RMSE greater than $30 \%$ ) for dry year (2015) showed that HERMES model should be recalibrated to improve estimation of soil moisture, especially under water stress (dry year 2015). The continued additional measurements conducted on the same experimental field would likely improve the estimation of soil water moisture.

4. The results obtained in simulation show also higher soil moisture under NT than CT system, but simulated differences between SM under both practices were smaller than those obtained in the measurement.

\section{ACKNOWLEDGEMENTS}

This study has been financed from IUNG-PIB Multiannual program supported by the Ministry of Agriculture and Rural Development Supporting actions for protection and rational use of agricultural production space in Poland and ensuring the quality of plant raw materials - Task 1.7. 


\section{REFERENCES}

[1] Ahmadi, S.H., Mosallaeepour, E., Kamgar-Haghighi, A.A., Sepaskhah, A.R., 2015. Modeling maize yield and soil water content with AquaCrop under full and deficit irrigation managements. Water Resour. Manag., 29, 2837-2853, DOI: 10.1007/s11269-015-0973-3.

[2] Basche, A.D., Kaspar, T.C., Archontoulis, S.V., Jaynes, D.B., Sauer, T.J., Parkin, T.B., Miguez, F.E., 2016. Soil water improvements with the long-term use of a winter rye cover crop. Agric. Water Manag., 172, 40-50, DOI: 10.1016/j.agwat.2016.04.006.

[3] Bednarek, R., Owczarzak, W., Mocek-Płóciniak, A., Dąbrowski, M., 2015. The impact of corn tillage system on the properties of organic matter in the humus horizon of black earth (haplic phaeozems) in poznański lake district. Pol. J. Soil Sci., 46.1, 87-95, DOI: 10.17951/ pjss.2013.46.1.87.

[4] Blanco-Canqui, H., Wienhold, B.J., Jin, V.L., Schmer, M.R., Kibet, L.C., 2017. Long-term tillage impact on soil hydraulic properties. Soil Tillage Res., 170, 38-42, DOI: 10.1016/j. still.2017.03.001.

[5] Blecharczyk, A., Malecka, I., Sierpowski, J., 2007. Long-term effects of tillage systems on physico-chemical soil properties (in Polish). Fragm. Agron., 1, 7-13.

[6] Blecharczyk, A., Malecka, I., Skrzypczak, G., 2004. Effect of reduced tillage on yield, weed infestation of maize and soil properties (in Polish). Acta Sci. Pol. Agric., 3, 157-163.

[7] Busari, M.A., Kukal, S.S., Kaur, A., Bhatt, R., Dulazi, A.A., 2015. Conservation tillage impacts on soil, crop and the environment. Int. Soil Water Conserv. Res., 3, 119-129, DOI: 10.1016/j.iswcr.2015.05.002.

[8] Chi, J., Waldo, S., Pressley, S., O'Keeffe, P., Huggins, D., Stöckle, C., Pan, W.L., Brooks, E., Lamb, B., 2016. Assessing carbon and water dynamics of no-till and conventional tillage cropping systems in the inland Pacific Northwest US using the eddy covariance method. Agric. For. Meteorol., 218, 37-49, DOI: 10.1016/j.agrformet.2015.11.019.

[9] Copec, K., Filipovic, D., Husnjak, S., Kovacev, I., Kosutic, S., 2016. Effects of tillage systems on soil water content and yield in maize and winter wheat production. Plant Soil Environ., 61, 213-219, DOI: 10.17221/156/2015-PSE.

[10] Czyż, E., 2011. Effects of cultivation of maize (Zea mays L.) in monoculture and crop rotation on some soil physical properties (in Polish). Soil Sci. Ann., 62.1, 12-24.

[11] Czyż, E.A., Dexter, A.R., 2010. Effects of different cultivation technologies on soil bulk density and penetration resistance (in Polish). Soil Sci. Ann., 61.4, 40-50.

[12] Czyż, E.A., Dexter, A.R., 2008. Soil physical properties under winter wheat grown with different tillage systems at selected locations. Int Agrophysics, 22, 191-201.

[13] Doorenbos, J., 1975. Guidelines for predicting crop water requirements. Food Agric. Organ. Rome Irrig. Drain. Pap., 24.

[14] Fabrizzi, K.P., Garcia, F.O., Costa, J.L., Picone, L.I., 2005. Soil water dynamics, physical properties and corn and wheat responses to minimum and no-tillage systems in the southern Pampas of Argentina. Soil Tillage Res., 81, 57-69, DOI: 10.1016/j.still.2004.05.001.

[15] Graß, R., Thies, B., Kersebaum, K.-C., Wachendorf, M., 2015. Simulating dry matter yield of two cropping systems with the simulation model HERMES to evaluate impact of future climate change. Eur. J. Agron., 70, 1-10, DOI: 10.1016/j.eja.2015.06.005.

[16] Hernández, M., Echarte, L., Della Maggiora, A., Cambareri, M., Barbieri, P., Cerrudo, D., 2015. Maize water use efficiency and evapotranspiration response to $N$ supply under contrasting soil water availability. Field Crops Res., 178, 8-15, DOI: 10.1016/j.fcr.2015.03.017.

[17] Holland, J.M., 2004. The environmental consequences of adopting conservation tillage in Europe: reviewing the evidence. Agric. Ecosyst. Environ., 103, 1-25, DOI: 10.1016/j.agee.2003.12.018.

[18] Kersebaum, K.C., 2011. Special features of the HERMES model and additional procedures for parameterization, calibration, validation, and applications. Methods Introd. Syst. Models Agric. Res., 65-94, DOI: 10.2134/advagricsystmodel2.c2. 
[19] Kersebaum, K.C., 2007. Modelling nitrogen dynamics in soil-crop systems with HERMES. Nutr. Cycl. Agroecosystems, 77, 39-52, DOI: 10.1007/s10705-006-9044-8.

[20] Kersebaum, K.C., 1995. Application of a simple management model to simulate water and nitrogen dynamics. Ecol. Model., 81, 145-156, DOI: 10.1016/0304-3800(94)00167-G.

[21] Kersebaum, K.C., Lorenz, K., Reuter, H.I., Schwarz, J., Wegehenkel, M., Wendroth, O., 2005. Operational use of agro-meteorological data and GIS to derive site specific nitrogen fertilizer recommendations based on the simulation of soil and crop growth processes. Phys. Chem. Earth Parts ABC, 30, 59-67, DOI: 10.1016/j.pce.2004.08.021.

[22] Kersebaum, K.C., Mirschel, W., Wenkel, K.O., Manderscheid, R., Weige, H.J., Nendel, C., 2009. Modelling climate change impacts on crop growth and management in Germany. Clim. Var. Model. Tools Agric. Decis.-Mak. Nova Sci. Publ. N.Y. USA, 183-194.

[23] Liu, S., Yang, J.Y., Zhang, X.Y., Drury, C.F., Reynolds, W.D., Hoogenboom, G., 2013. Modelling crop yield, soil water content and soil temperature for a soybean-maize rotation under conventional and conservation tillage systems in Northeast China. Agric. Water Manag., 123, 32-44, DOI: 10.1016/j.agwat.2013.03.001.

[24] Machul, M., 2007. Possibilities and implications of using reduced tillage and direct sowing in maize cultivation (in Polish). Stud. Rap. IUNG-PIB, 9, 159-170.

[25] Małecka-Jankowiak, I., Blecharczyk, A., Faligowska, A., Szukała, J., Waniorek, B., 2015. Effect of irrigation and tillage systems on the physical properties in soil under yellow and narrow-leaved lupin (in Polish). Fragm. Agron., 32, 43-52.

[26] Michalczyk, A., Kersebaum, K.C., Roelcke, M., Hartmann, T., Yue, S.-C., Chen, X.-P., Zhang, F.-S., 2014. Model-based optimisation of nitrogen and water management for wheatmaize systems in the North China Plain. Nutr. Cycl. Agroecosystems, 98, 203-222.

[27] Mkoga, Z.J., Tumbo, S.D., Kihupi, N., Semoka, J., 2010. Extrapolating effects of conservation tillage on yield, soil moisture and dry spell mitigation using simulation modelling. Phys. Chem. Earth Parts ABC 35, 686-698, DOI: 10.1016/j.pce.2010.07.036.

[28] Mupangwa, W., Jewitt, G.P.W., 2011. Simulating the impact of no-till systems on field water fluxes and maize productivity under semi-arid conditions. Phys. Chem. Earth Parts ABC, 36, 1004-1011, DOI: 10.1016/j.pce.2011.07.069.

[29] Naresh, R.K., Singh, S.P., Dwivedi, A., Sepat, N.K., Kumar, V., Ronaliya, L.K., Kumar, V., Singh, R., 2013. Conservation Agriculture Improving Soil Quality for Sustainable Production Systems under Smallholder Farming Conditions in North West India: A Review. Int. J. Life Sci. Bot. Pharm. Res., 2, 151-213.

[30] Palosuo, T., Kersebaum, K.C., Angulo, C., Hlavinka, P., Moriondo, M., Olesen, J.E., Patil, R.H., Ruget, F., Rumbaur, C., Takáč, J., 2011. Simulation of winter wheat yield and its variability in different climates of Europe: a comparison of eight crop growth models. Eur. J. Agron., 35, 103-114, DOI: 10.1016/j.eja.2011.05.001.

[31] Pohanková, E., Trnka, M., Hlavinka, P., Takáč, J., Žalud, Z., 2013. Calibration of the crop growth models for winter wheat, in: MendelNet: Proceedings of International PhD Students Conference, pp. 130-135.

[32] Rötter, R.P., Palosuo, T., Kersebaum, K.C., Angulo, C., Bindi, M., Ewert, F., Ferrise, R., Hlavinka, P., Moriondo, M., Nendel, C., 2012. Simulation of spring barley yield in different climatic zones of Northern and Central Europe: a comparison of nine crop models. Field Crops Res., 133, 23-36, DOI: 10.1016/j.fcr.2012.03.016.

[33] Sommer, R., Piggin, C., Haddad, A., Hajdibo, A., Hayek, P., Khalil, Y., 2012. Simulating the effects of zero tillage and crop residue retention on water relations and yield of wheat under rainfed semiarid Mediterranean conditions. Field Crops Res., 132, 40-52,

DOI: $10.1016 /$ j.fcr.2012.02.024.

[34] Su, Z., Zhang, J., Wu, W., Cai, D., Lv, J., Jiang, G., Huang, J., Gao, J., Hartmann, R., Gabriels, D., 2007. Effects of conservation tillage practices on winter wheat water-use efficiency and crop yield on the Loess Plateau, China. Agric. Water Manag., 87, 307-314, DOI: 10.1016/j.agwat.2006.08.005. 
[35] Trnka, M., Dubrovský, M., Semerádová, D., Žalud, Z., 2004. Projections of uncertainties in climate change scenarios into expected winter wheat yields. Theor. Appl. Climatol., 77, 229-249.

[36] Wimmerova, M., Pohanková, E., Christian, K., Kersebaum, M.T., Zalud, Z., Hlavinka, P., 2016. Assessing the impact of drought stress on winter wheat canopy by HERMES crop growth model, in: MendelNet: Proceedings of International PhD Students Conference, 189-194.

[37] Włodek, S., Biskupski, A., 2011. The dynamics of haplic luvisol moisture in many-years experiment with different systems of tillage (in Polish). Soil Sci. Ann., 62.1, 221-225.

[38] Włodek, S., Biskupski, A., Pabin, J., 2008. Dynamics of moisture contents in the upper soil layer at different systems of tillage (in Polish). Soil Sci. Ann., 59(1), 221-225.

[39] Włodek, S., Biskupski, A., Pabin, J., Kaus, A., 2007. Yielding of crops and changes in soil water retention under different systems of tillage (in Polish). Agricultural Engineering, 11, 195-200. 